\title{
Plant Growth Promoting Traits of Phosphate Solubilizing Bacteria Isolated from Agricultural Lands in Sothern Sri Lanka
}

\author{
B.C. Walpola* and R.H.A.N. Hettiarachchi
}

\begin{abstract}
Inorganic phosphate solubilization by phosphate solubilizing bacteria (PSB) is known to be one of the major mechanisms associated with plant growth promotion. The use of plant growth-promoting bacteria as bio-inoculants/bio-fertilizers is thus considered to be an environmentally friendly approach of soil enrichment. Fifteen PSB from different agricultural lands including terrestrial, aqua and swamp regions of Southern Sri Lanka were isolated using serial dilution plating on NBRIP agar plates and screened for various plant growthpromoting traits. The highest phosphate solubilization $(1127 \mu \mathrm{g} / \mathrm{ml})$ was exhibited in PSB-14 which was identified as Enterobacter sp. IAA production was detected by 6 strains and among them, bacterial isolate PSB-12 showed the highest IAA production $(24.2 \mu \mathrm{g} / \mathrm{ml})$ followed by PSB-7 and PSB-1 (21.3 and $20.9 \mu \mathrm{g} / \mathrm{ml}$ respectively). Except for PSB-8
\end{abstract}

Department of Soil Science, Faculty of Agriculture, University of Ruhuna, Mapalana, Kamburupitiya,

Sri Lanka.

*bcwalpola@soil.ruh.ac.lk

http://orcid.org/0000-0002-4663-0943

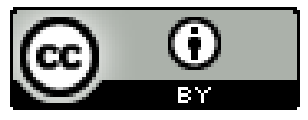

This article is published under the terms of the Creative Commons Attribution 4.0 International License, which permits unrestricted use, distribution and reproduction in any medium provided the original author and source are credited. and PSB-13 strains, all the other isolated strains showed a positive response for ammonia production. Except for PSB-2, PSB-7, PSB-10 and PSB-11, all the other studied isolates showed $\mathrm{HCN}$ production. PSB-3, PSB-9 and PSB-14 isolates were found to be strong $\mathrm{HCN}$ producers. All the strains showed catalase activity implying that they were capable of growing under stress conditions. PSB-1, PSB-12, PSB-14 and PSB-15 strains showed all the tested plant growth promotion traits.

Keywords: IAA production, Plant growth-promoting rhizobacteria, Phosphate solubilizing bacteria, Phosphate solubilization

\section{INTRODUCTION}

Phosphorus $(\mathrm{P})$ is known to be a major macronutrient having a defined role in the growth and development of plants (Awasthi et al., 2011). Though the majority of agricultural soils contain a high reserve of $\mathrm{P}$, the concentration of available $\mathrm{P}$ in soil is generally very low (0.4-1.2 g/kg) (Fernández et al., 2014; Joe et al., 2018). Furthermore, a certain portion of the applied phosphorus fertilizers is immobilized into insoluble forms with $\mathrm{Al}$ or $\mathrm{Fe}$ in acid soils or with Ca in calcareous soils (Mundra et al., 
2011). In this context, the role of phosphate solubilizing microorganisms (PSMs) is important as they are effectively involved in the solubilization of insoluble inorganic phosphates (Khan et al., 2010). Phosphorus-solubilizing activity is considered to be the most important among the multiple properties of the soil microorganisms that promote plant growth and nutrient absorption.

In addition, they enhance plant growth via synthesis of phytohormones such as auxins (Jeon et al., 2003; Egamberdiyeva, 2005), cytokinins (Gracia de Salamone et al., 2001), and gibberellins (Gutierrez-Manero et al., 2001) or other growth-promoting or protecting substances like siderophores (Wani et al., 2007), hydrogen cyanide (Kang et al., 2010), enzymes and/or fungicidal compounds such as chitinase, cellulose, protease (Dey et al., 2004; Lucy et al., 2004; Hamdali et al., 2008) which ensure antagonism against phytopathogenic microorganisms. Among plant growth-promoting bacterial strains, rhizobia are involved in the symbiotic fixation of atmospheric nitrogen with legumes (Satyaprakash et al., 2017). Therefore, PSMs (Phosphate solubilizing microorganisms) may effectively contribute towards the enhancement of the plant performance while improving the efficiency of chemical fertilizers (Bechtaoui et al., 2019). Bacterial species belonging to genera Pseudomonas, Azospirillum, Azotobacter, Klebsiella, Enterobacter, Alcaligenes, Arthrobacter, Burkholderia, Bacillus and Serratia are well-known phosphate solubilizers (Satyaprakash et al., 2017). Chamikara (2019) isolated Pseudomonas aeruginosa, Achromobacter xylosoxidans and Pseudomonas fluorescens, Bacillus subtilis respectively from Aloe vera and mung bean cultivated soils in Sri Lanka.

In Sri Lanka, the available information about the phosphate solubilizing plant growth-promoting rhizobacteria is generally poor. In this context, the objectives of the present study were to isolate phosphate solubilizing bacterial strains and assess their plant growth-promoting characteristics.

\section{MATERIALS AND METHODS}

\section{Isolation of Strains and Phosphate Solubilization}

Soils used in this study to isolate phosphate solubilizing microorganisms were locally collected from rhizosphere soil samples from different agricultural 
lands in Southern Sri Lanka (Latitude: from $6.009460 \mathrm{~N}$ to $6.163220 \mathrm{~N}$ and longitude: from $80.473530 \mathrm{E}$ to 80.676000E). Each rhizosphere soil sample was collected by carefully uprooting a plant and shaking the soil adhering to the roots into a sterile polythene bag. The soil samples were immediately transported to the laboratory for further study.

A $10 \mathrm{~g}$ of field moist soil from each soil sample was weighed and transferred to a $250 \mathrm{ml}$ Erlenmeyer flask containing sterilized $90 \mathrm{ml}$ of $0.85 \%$ $\mathrm{NaCl}$ solution. The mixture was then shaken for 30 minutes at approximately $150 \mathrm{rpm}$. Immediately after shaking, a series of tenfold dilutions of the suspension was made by pipetting $1 \mathrm{ml}$ aliquots into sterilized $9 \mathrm{ml}$ of $0.85 \%$ $\mathrm{NaCl}$ solution. Aliquots of $0.1 \mathrm{ml}$ of the sample from each of these dilutions were spread on to a petri dish with National Botanical Research Institute Phosphorus (NBRIP) medium containing $10 \mathrm{~g}$ of glucose, $5 \mathrm{~g}$ of $\mathrm{Ca}_{3}\left(\mathrm{PO}_{4}\right)_{2}, 5 \mathrm{~g}$ of $\mathrm{MgCl}_{2} .6 \mathrm{H}_{2} \mathrm{O}, 0.25 \mathrm{~g}$ of $\mathrm{MgSO}_{4} .7 \mathrm{H}_{2} \mathrm{O}, 0.2 \mathrm{~g}$ of $\mathrm{KCl}$ and $0.1 \mathrm{~g}$ of $\left(\mathrm{NH}_{4}\right)_{2 \mathrm{SO}_{4}}$ in $1 \mathrm{~L}$ distilled water (Nautiyal, 1999). The $\mathrm{pH}$ of the media was adjusted to 7 using $\mathrm{HCl}$. The plates were incubated for 7 days in an incubator at $30{ }^{\circ} \mathrm{C}$. The colonies with clear halos are considered to be phosphate solubilizing colonies. Predominant colonies were further purified by re-streaking on the fresh NBRIP agar plates at $30{ }^{\circ} \mathrm{C}$. Fifteen bacterial strains that exhibited large clear zones on the agar plates were selected as phosphorus solubilizing strains for further study (Figure 1).

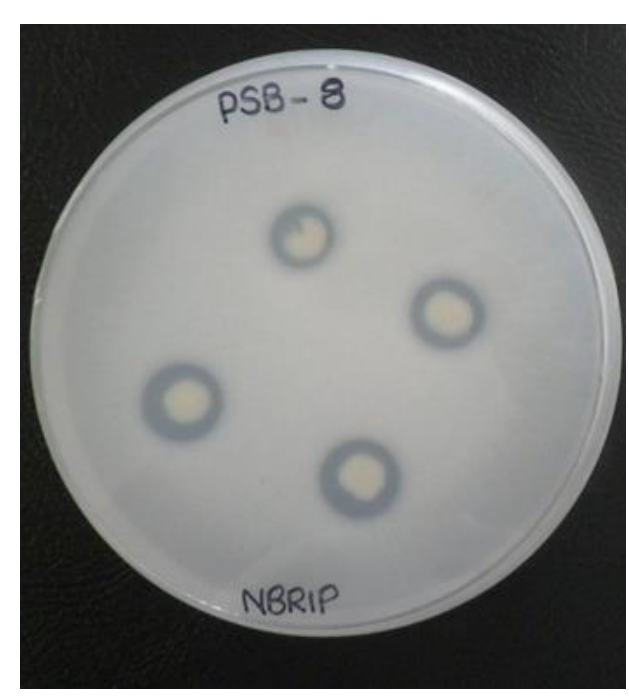

Figure 1. Isolated phosphate solubilizing bacterial strain (PSB-8) showing clear halos produced in NBRIP solid medium.

Isolated bacterial strains were inoculated on agar media and cultured for $48 \mathrm{~h}$ at $30{ }^{\circ} \mathrm{C}$. The bacterial colony shape and colour were observed to study the morphological aspects of the colonies. Gram staining of purified PSB was performed according to the Vincent method (Vincent, 1970) and 
was observed under a microscope (VanGuard 1400 series) (Figure 2).

Bacterial strains were grown in sterilized liquid NBRIP medium $(20 \mathrm{ml})$ at $30{ }^{\circ} \mathrm{C}$ for 2 days with continuous shaking at $150 \mathrm{rpm}$. Aliquots of culture (1 ml) were then transferred to a $500 \mathrm{ml}$ flask ( $\mathrm{n}=3$ per strain) containing sterilized liquid NBRIP medium (200 $\mathrm{ml}$ ) and incubated for 7 days with continuous shaking at $30{ }^{\circ} \mathrm{C}$. Sterilized un-inoculated medium served as a control. A sample $(10 \mathrm{ml})$ of each cultured and control were taken daily and centrifuged at $8000 \mathrm{rpm}$ for $15 \mathrm{~min}$.

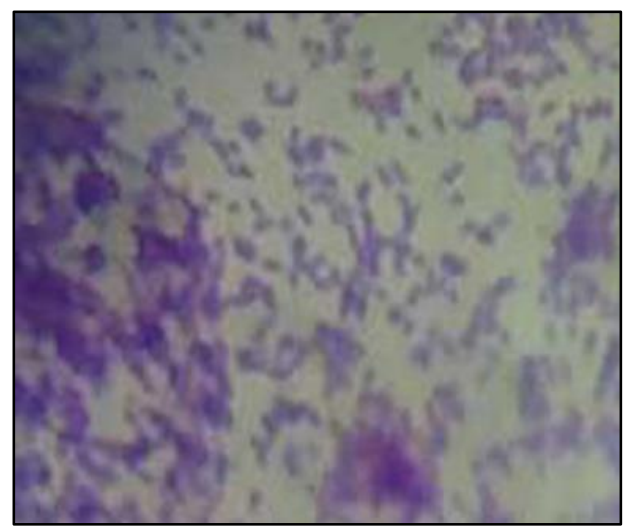

Figure 2. Gram-positive phosphate solubilizing bacterial isolate (PSB-9).

The clear supernatant was used in determining the amount of phosphorous released into the medium according to the phospho-molybdate blue color method (Murphy and Riley, 1962).

\section{Plant Growth-promoting Traits of Isolated PSB \\ Production of Indole Acetic Acid}

Bacterial strains were grown in sterilized $100 \mathrm{ml}$ liquid NBRIP media containing $1 \mathrm{ml}$ of $0.2 \%$ tryptophan and incubated for $72 \mathrm{hrs}$ with continuous shaking at $30 \quad{ }^{\circ} \mathrm{C}$. A sterilized uninoculated medium was served as the control. Each was taken into a centrifugation tube every $24 \mathrm{hrs}$ and centrifuged $10 \mathrm{~min}$ at $12000 \mathrm{rpm}$. The clear supernatant was used to determine IAA production as described by Gutierrez et al. (2009). Clear supernatant of $1 \mathrm{ml}$ was mixed with 4 $\mathrm{ml}$ of the Salkowski's reagent $(50 \mathrm{ml}$ of $35 \%$ perchloric acid and $1 \mathrm{ml}$ of $0.05 \mathrm{M}$ $\mathrm{FeCl}_{3}$ solution). The mixture was incubated in the dark at $37{ }^{\circ} \mathrm{C}$ for 30 minutes. Development of pink colour indicated IAA production and optical density was taken at $530 \mathrm{~nm}$ using UV spectrophotometer (Shimadzu-UV mini 1240). The concentration of IAA produced by cultures was measured with the help of a standard graph of IAA obtained in the range of 10 to 100 $\mu \mathrm{g} \mathrm{ml-1}$. 
Production of Ammonia

The bacterial isolates were tested for the production of ammonia in peptone water. Fresh cultures were inoculated into $10 \mathrm{ml}$ peptone water and incubated for $48 \mathrm{hrs}$ at $30^{\circ} \mathrm{C}$. Nessler's reagent (0.5 $\mathrm{ml}$ ) was added to each bacterial suspension. The development of brown to yellow colour was considered to be a positive response for ammonia production (Cappucino and Sherman, 1992).

\section{Production of Hydrogen Cyanide}

HCN production was tested by growing bacteria in the $10 \%$ tryptic soy agar (TSA) supplemented with glycine (4.4 $\left.\mathrm{g} \mathrm{L}^{-1}\right)$. A filter paper previously soaked in picric acid and $\mathrm{Na}_{2} \mathrm{CO}_{3}(0.5 \%$ and $2 \%$, respectively) solution was fixed onto the underside of the lids of plates and incubated for 5 days at $30^{\circ} \mathrm{C}$. A change in filter paper colour from yellow to orange-brown was considered to be the indication of $\mathrm{HCN}$ production (Donate-Correa et al., 2004).

\section{Catalase Activity}

Isolates were grown on nutrient agar media at $30{ }^{\circ} \mathrm{C}$ for $24-48 \mathrm{hrs}$. A loop-full of each culture was mixed with $50 \mu$ of
$3 \%(\mathrm{v} / \mathrm{v})$ hydrogen peroxide $\left(\mathrm{H}_{2} \mathrm{O}_{2}\right)$ on a glass slide and incubated at room temperature for $1 \mathrm{~min}$ to observe the evolution of oxygen which was recorded as positive for catalase reaction (Chaiharn and Lumyong, 2009).

Each of the above tests was based on three repeat experiments and triplicated per bacterium.

\section{Identification of the Best Bacterial Strain}

Partial sequencing of $16 \mathrm{~S}$ rRNA for the bacterial strain was performed with the help of a DNA sequencing service (Solgent, Daejeon, South Korea) with universal primers, 27F (5'AGAGTTTGATCCTGGCTCAG -3'), and 1492R (5'-GGTTACCTTGTT ACGACTT-3') (Weisburg et al., 1991). The online program BLAST (NCBI, 2019) was used in identifying the related sequences with known taxonomic information available at the databank of the National Center for Biotechnology Information (NCBI, Bethesda, Maryland, USA). A phylogenetic tree was constructed with the CLUSTAL X program (Thompson et al., 1997), which involved sequence alignment by the neighbour-joining 
method (Saitou and Nei, 1987) and maximum parsimony with the MEGA4 program (Kumar et al., 2001). The grouping of sequences was based on confidence values obtained by bootstrap analysis of 1000 replicates. Gaps were edited in the BioEdit program (Hall, 1999) and evolutionary distances were calculated by Kimura's two-parameter model (Kimura, 1980). Reference sequences were retrieved from GenBank under the accession numbers indicated in the trees.

\section{Statistical Analysis}

Data were subjected to ANOVA with the SAS package (SAS Institute, 1999).

\section{RESULTS AND DISCUSSION}

\section{Isolation of Strains and Phosphate Solubilization}

A total of 15 bacterial isolates (PSB-1 to PSB-15) that exhibited clear zones around the colony after 3 days of incubation were selected as phosphatesolubilizing organisms. All the isolated PSB strains were odourless, had rod and round raised colonies with a smooth and shiny surface. Most of them had white colour colonies except PSB-5, PSB-6, PSB-13 and PSB-15 which had yellow colour colonies. Out of 15 bacterial isolates, 8 isolates (PSB-3, PSB4, PSB-7, PSB-9, PSB-10, PSB-11, PSB-12, PSB-14) showed positive response for gram staining.

To authenticate the isolated PSB, which formed a clear zone around the colonies, their phosphate solubilization ability was measured using a liquid NBRIP medium. Significantly higher amount of phosphate solubilization was shown in PSB-1 (916 $\mu \mathrm{g} / \mathrm{ml})$, PSB-3 (1030 $\mu \mathrm{g} / \mathrm{ml})$, PSB-9 $(925 \mu \mathrm{g} / \mathrm{ml})$ and $\mathrm{PSB}=14(1127 \mu \mathrm{g} / \mathrm{ml})$ compared to all the other bacterial strains after 5 days of incubation (Table 1). A rapid increase of available phosphorus contents in the liquid medium was observed during the first 5 days of the incubation followed by a gradual decrease towards the end of the incubation. In the case of control, no phosphate solubilization was observed throughout the incubation period. The phosphate solubilization is associated with the production of low molecular weight organic acids such as gluconic acids, oxalic acids, citric acids, succinic acids, etc. (Chaiharn and Lumyong, 2009; Gulati et al., 2010). The reduction of available phosphorous content in later stages of the incubation may be due to consumption of the available 
phosphorous or depletion of nutrients in the culture medium, in particular, carbon source that is essential for the production of organic acids and microbial activity (Chaiharn and Lumyong, 2009).

However, as reported by VarshaNarsian et al. (1994), the availability of soluble phosphorus in the culture medium might also have an inhibitory effect on further phosphate solubilization. Excretory toxic products may also responsible for such reduction in P-solubilization.
Production of Indole Acetic Acid

Besides phosphate solubilization, the production of phytohormones by phosphate solubilizing microorganisms in the soil can promote plant growth. As stated by previous studies, some strains of PSB can produce a relatively high amount of IAA in a nutrient broth medium supplemented with tryptophan (Nacoon et al., 2020; Gusain et al., 2015; Walpola and Arunakumara, 2015). Among the phytohormones, the auxin IAA, applied at low concentrations, is known to stimulate

Table 1. Quantity of phosphate solubilization by phosphate solubilizing bacteria at 1, 3, 5 and 7 days after inoculation.

\begin{tabular}{|c|c|c|c|c|}
\hline & $\begin{array}{l}\text { Phosphate } \\
\text { solubilization } \\
(\mu \mathrm{g} / \mathrm{ml}) \\
\text { Day } 1\end{array}$ & $\begin{array}{l}\text { Phosphate } \\
\text { solubilization } \\
(\mu \mathrm{g} / \mathrm{ml}) \\
\text { Day } 3\end{array}$ & $\begin{array}{l}\text { Phosphate } \\
\text { solubilization } \\
(\mu \mathrm{g} / \mathrm{ml}) \\
\text { Day } 5\end{array}$ & $\begin{array}{l}\text { Phosphate } \\
\text { solubilization } \\
(\mu \mathrm{g} / \mathrm{ml}) \\
\text { Day } 7\end{array}$ \\
\hline PSB 1 & $98.9 \pm 13.4$ & $379.2 \pm 15.6$ & $916.3 \pm 16.4$ & $748.8 \pm 15.4$ \\
\hline PSB 2 & $82.9 \pm 13.1$ & $279.9 \pm 13.9$ & $456.1 \pm 14.5$ & $358.5 \pm 13.8$ \\
\hline PSB 3 & $101.7 \pm 13.5$ & $410.2 \pm 14.2$ & $1030.3 \pm 11.3$ & $973.5 \pm 10.2$ \\
\hline PSB 4 & $102.2 \pm 13.8$ & $255.4 \pm 13.5$ & $869.1 \pm 13.9$ & $749.4 \pm 18.5$ \\
\hline PSB 5 & $95.1 \pm 12.5$ & $509.7 \pm 14.6$ & $767.6 \pm 14.1$ & $707.1 \pm 14.8$ \\
\hline PSB 6 & $54.4 \pm 12.1$ & $472.3 \pm 14.1$ & $741.9 \pm 15.1$ & $678.5 \pm 13.8$ \\
\hline PSB 7 & $62.4 \pm 8.9$ & $506.8 \pm 15.4$ & $654.9 \pm 11.8$ & $586.8 \pm 9.5$ \\
\hline PSB 8 & $60.4 \pm 9.7$ & $611.0 \pm 14.5$ & $850.9 \pm 12.4$ & $784.6 \pm 9.5$ \\
\hline PSB 9 & $68.1 \pm 8.5$ & $598.7 \pm 14.6$ & $925.2 \pm 9.4$ & $846.6 \pm 11.5$ \\
\hline PSB 10 & $87.4 \pm 7.5$ & $466.2 \pm 13.4$ & $873.9 \pm 8.9$ & $811.8 \pm 12.6$ \\
\hline PSB 11 & $44.0 \pm 5.7$ & $502.5 \pm 12.4$ & $777.9 \pm 10.4$ & $706.7 \pm 8.4$ \\
\hline PSB 12 & $88.9 \pm 9.4$ & $417.6 \pm 11.4$ & $623.4 \pm 11.7$ & $547.8 \pm 7.8$ \\
\hline PSB 13 & $62.9 \pm 7.8$ & $589.4 \pm 15.6$ & $874.3 \pm 13.5$ & $794.5 \pm 8.9$ \\
\hline PSB 14 & $77.5 \pm 8.8$ & $651.8 \pm 15.7$ & $1127.0 \pm 14.3$ & $1036.7 \pm 14.8$ \\
\hline PSB 15 & $59.3 \pm 6.7$ & $431.9 \pm 14.5$ & $356.8 \pm 8.5$ & $316.3 \pm 7.8$ \\
\hline
\end{tabular}

Values given here are the means $(n=3) \pm$ standard deviation. 
both a rapid response (e.g. increased cell elongation) and a long-term response (e.g. cell division and differentiation) in plants (Elhaissoufi et al., 2020). The amount of IAA produced by plant growth-promoting bacteria can vary among different species and strains, and it is also influenced by culture condition, growth stage and availability of substrates such as amino acids (Gusain et al., 2015). The IAA production by isolated phosphate solubilizing microorganisms is shown in Figure 3. Out of 15 isolates, 6 bacterial isolates were able to produce IAA in a nutrient broth medium supplemented with tryptophan. The bacterial isolate PSB-12 showed the highest IAA production $(24.2 \mu \mathrm{g} / \mathrm{ml})$ followed by PSB-7 and PSB-1 (21.3 and $20.9 \mu \mathrm{g} / \mathrm{ml}$ respectively).

In spite of being good IAA producers, these three bacterial strains (PSB-12, PSB-7 and PSB-1) efficiently solubilized inorganic phosphate in NBRIP culture medium.

All the isolates exhibited the highest IAA production within $24-48$ hrs followed by reduction as time progressed. Previous studies by Nutaratat et al. (2017), Ozdal et al. (2016) and Swain et al. (2007) also observed the maximum IAA production during the

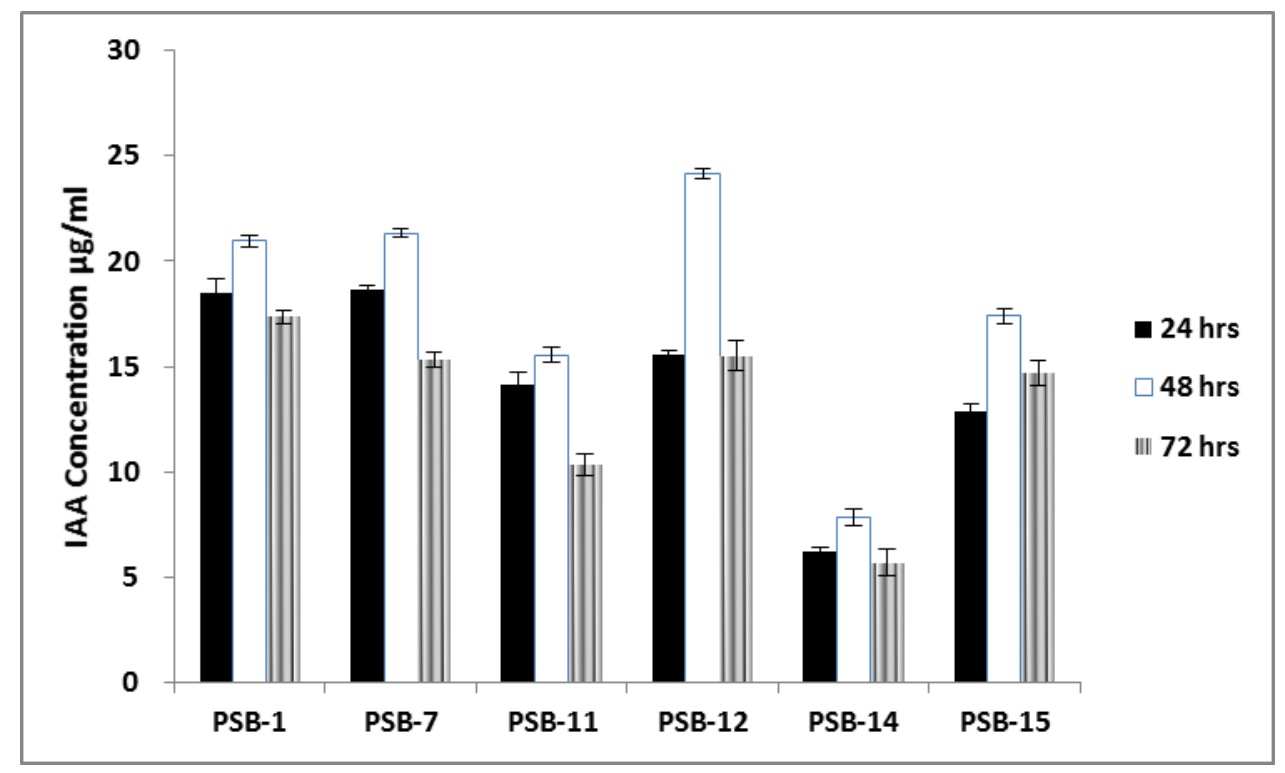

Values given here are the means $(n=3) \pm$ standard deviation

Figure 3. IAA production of isolated phosphorus solubilizing bacterial strains. 
stationary phase of the growth where the production occurred when the growth reached the maximal level, though the duration of the stationary phase depends on the species (Nutaratat et al., 2017).

The increase of IAA production during the early stages of the incubation may be attributed to the greater availability of the precursor as reported by Bharucha et al. (2013) who also observed increased IAA production up to 96 hours. The reduction in IAA production in later stages might be due to the release of IAA degrading enzymes such as IAA oxidase and peroxidase by the bacteria as reported by Bharucha et al. (2013).

\section{Production of Ammonia}

Among the plant growth-promoting activities, ammonia production also plays an important role in plant growth by the accumulation of nitrogen and helps in promoting root and shoot growth and biomass production indirectly (Marques et al., 2010). Production of this secondary metabolite was found in $>85 \%$ of the phosphate solubilizing isolates) except PSB-8 and PSB-13 (Table 2). The isolates PSB-5 showed the maximum ammonia production followed by PSB-14, PSB-6 and PSB-4. It was reported that the majority of rhizosphere associated bacteria (Rhizobacteria) possessed ammonia production (Thakur and Parikh, 2018). This observation is consistent with earlier reports, as all Serratia strains isolated from maize (Zea mays L.) rhizosphere (Agbodjato et al., 2015) and all Bacillus and Pseudomonas strains isolated from chickpea rhizosphere (Yadav et al., 2010) had shown positive response for ammonia production.

\section{Production of Hydrogen Cyanide}

Except for PSB-2, PSB-7, PSB-10 and PSB-11, all the studied isolates showed HCN production. PSB-3, PSB-9 and PSB-14 isolates were found to be strong $\mathrm{HCN}$ producers as they produced a brown colour in filter paper disc during assay for HCN production (Figure 4).

By synthesizing HCN, some bacteria inhibit plant disease development. By synthesizing $\mathrm{HCN}$, some bacteria inhibit plant disease development strengthening the host's disease resistance mechanism (Schippers et al., 1990). Thus the ability to produce $\mathrm{HCN}$ is considered as a desired quality of plant growth-promoting organisms. 
Table 2. Response of phosphorus solubilizing bacteria to qualitative assay of ammonia production.

\begin{tabular}{lc}
\hline Strain & Ammonia production \\
\hline PSB-1 & ++ \\
PSB-2 & +++ \\
PSB-3 & +++ \\
PSB-4 & +++ \\
PSB-5 & ++++ \\
PSB-6 & ++++ \\
PSB-7 & ++ \\
PSB-8 & - \\
PSB-9 & ++ \\
PSB-10 & ++ \\
PSB-11 & ++ \\
PSB-12 & ++ \\
PSB-13 & ++ \\
PSB-14 & - \\
PSB-15 & +++ \\
&
\end{tabular}

(+): positive response [Number of (+) marks express the intensity of activity], (-): Negative response
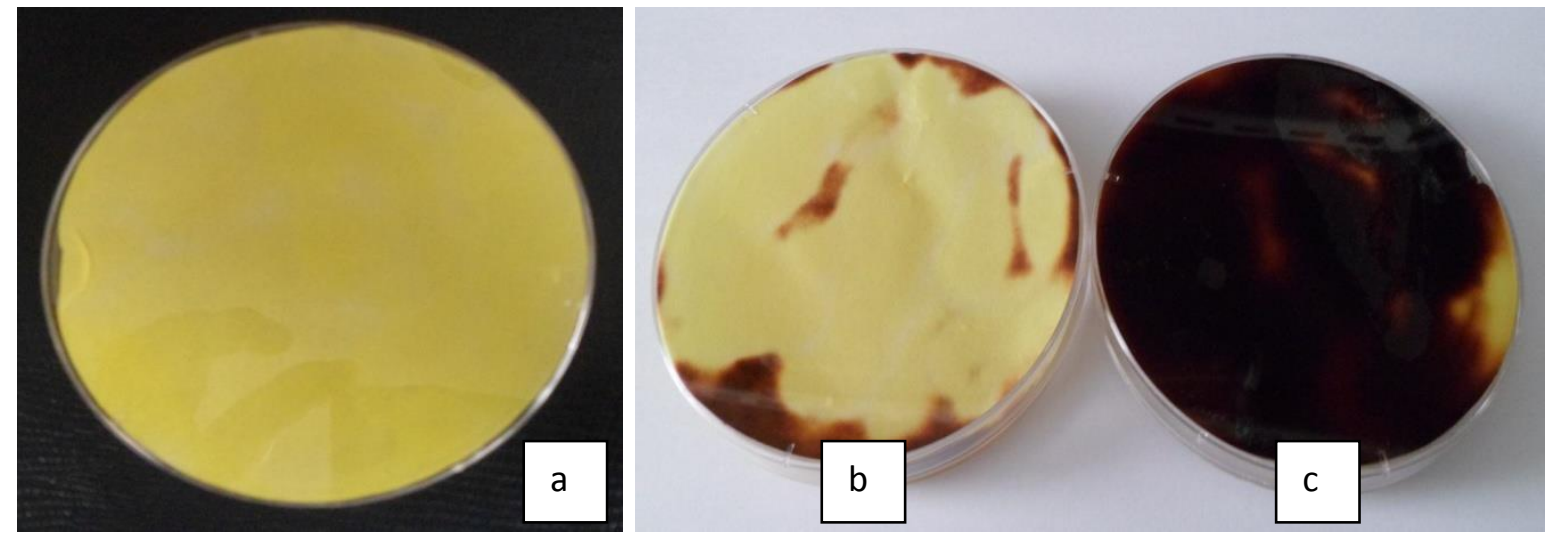

Figure 4. HCN production by the isolates (a) control no color change-negative for $\mathrm{HCN}$ production (b) light brown coloration - moderate HCN production (PSB-9) (c) dark brown coloration - strong HCN production (PSB-14). 
The presence of HCN in the soil can also act as an efficient biological weed control measure as it inhibits seed germination and seedling vigour (Banerjee et al., 2010). It has previously been reported that various bacterial genera capable of producing $\mathrm{HCN}$, including Alcaligenes, Aeromonas, Bacillus, Pseudomonas, Enterobacter and Rhizobium species isolated from various soil niches (Kumar et al., 2014).

\section{Catalase Activity}

Catalase activity is known to be an important trait of plant growthpromoting rhizobacteria as it could enhance the protection against hydrogen peroxide, a poisonous compound to bacteria and plant roots. Catalase removes the excess $\mathrm{H}_{2} \mathrm{O}_{2}$ produced in response to salt stress and therefore prevents leakage of $\mathrm{H}_{2} \mathrm{O}_{2}$ to other cell locations in the plants (Jamil et al., 2011). All the isolates in the present study showed a positive response for catalase activity correlating with previous studies (Bartakke et al., 2012; Bumunang and Babalola, 2014). Among them, PSB-3, PSB-7, PSB-12 and PSB-14 were found to exhibit the maximum activity.

\section{Phylogenetic Analysis}

Among the isolated bacterial strains, PSB-14 showed a remarkable ability in phosphate solubilization, IAA production, ammonia production, HCN production and catalase activity. Sequence alignment and phylogenetic tree drawn based on 165 rDNA gene sequences indicated that the species was Enterobacter cancerogenus (Figure 5). The sequence was deposited in the NCBI Genebank under accession numbers KX815170 (Enterobacter cancerogenus LMG 2693).

\section{CONCLUSION}

All the phosphate solubilizing bacterial strains have exhibited other plant growth promoting traits including IAA production, ammonia production, HCN production and catalase activity. Catalase activity was detected in all isolates while productions of indole acetic acid, ammonia, hydrogen cyanide were shown in $40 \%, 86 \%$ and $73 \%$ of isolates respectively. Further research with selected strains would be needed to confirm the practical acceptability of the strains for plant growth promotion via greenhouse and field experiments. 
B.C. Walpola and R.H.A.N. Hettiarachchi

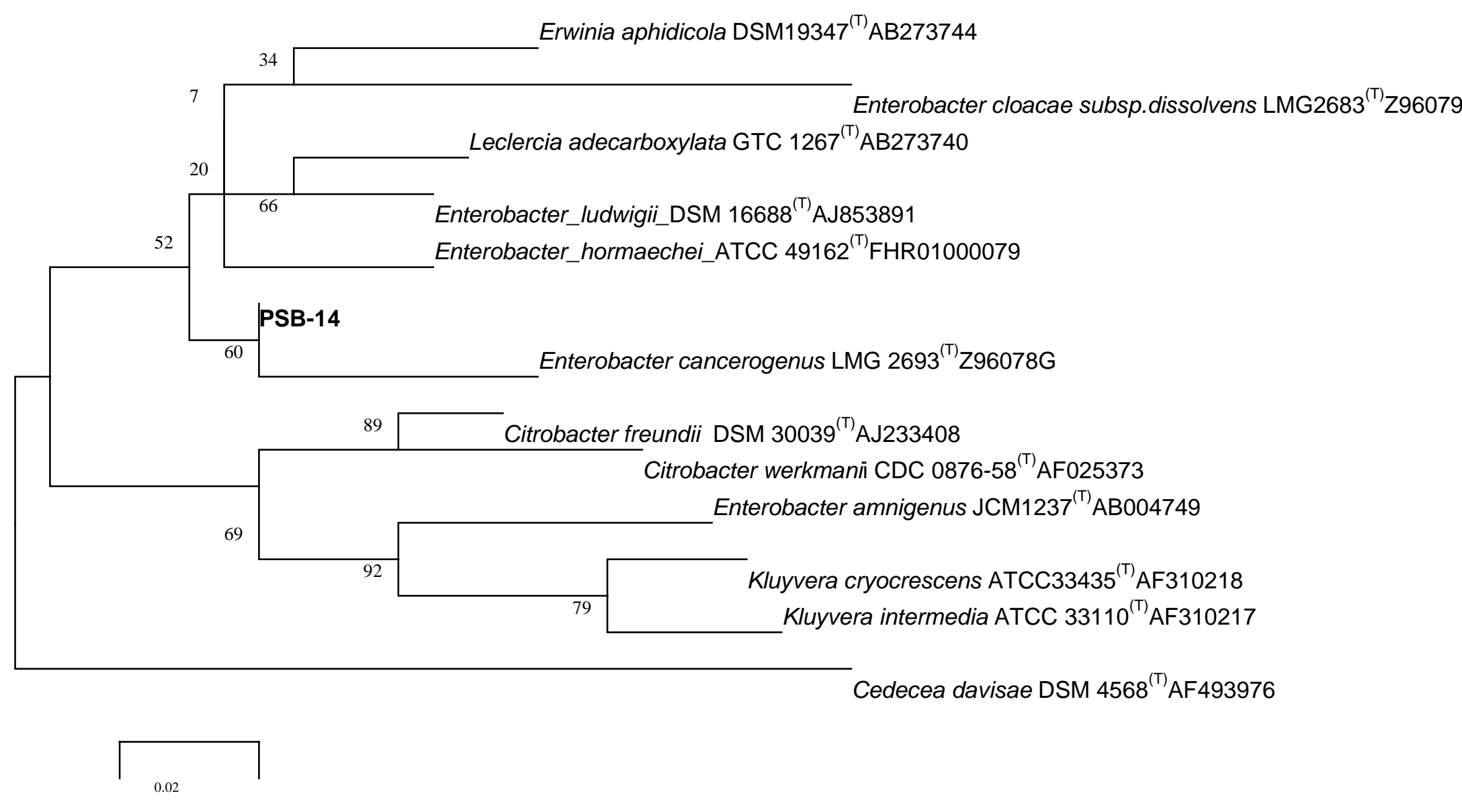

Figure 5. Phylogenetic tree based on $16 \mathrm{~S}$ rDNA gene sequences, showing the position of PSB-14, Enterobacter cancerogenus strain with respect to related species. The scale bar indicates 0.02 substitutions per nucleotide position. 


\section{REFERENCES}

Agbodjato, N. A., Noumavo, P. A., Baba-Moussa, F., Salami, H. A., Sina H., Sezan, A., Bankole, H., Adjanohoun, A. and Baba-Moussa, L. (2015). Characterization of potential plant growth-promoting rhizobacteria isolated from maize (Zea mays L.) in Central and Northern Benin (West Africa). Applied and Environmental Soil Science, DOI: https://doi.org/10.1155 /2015/901656

Awasthi, R., Tewari, R. and Nayyar, H. (2011). Synergy between plants and P-solubilizing microbes in soils: Effects on growth and physiology of crops. International Research Journal of Microbiology, 2: 484-503.

Banerjee, S., Palit, R., Sengupta, C. and Standing, D. (2010). Stress-induced phosphate solubilization by Arthrobacter sp. and Bacillus sp. isolated from tomato rhizosphere. Australian Journal of Crop Science, 4: 378-383.

Bartakke, G., Suryavanshi, M. and Kulkarni, C. S. (2012). Isolation of oxalotrophic phosphate solubilizing rhizobacteria and their screening for plant growth-promoting traits. Journal of Environmental Research and Development, 6: 734-737.

Bechtaoui, N., Raklami, A., Tahiri, A. I., Benidire, L., Alaoui, A. E. I., Meddich, A., Gottfert, M. and Oufdou, K. (2019). Characterization of plant growth-promoting rhizobacteria and their benefits on growth and phosphate nutrition of faba bean and wheat. Biology Open, 8, DOI: https://doi.org/10.1242/bio. 043968

Bharucha, U., Patel, K. and Trivedi, U. B. (2013). Optimization of indole acetic acid production by Pseudomonas putida UB1 and its effect as plant growth-promoting rhizobacteria on mustard (Brassica nigra). Agricultural Research, 2: 215 221.

Bumunang, E. W. and Babalola, O. O. (2014). Characterization of Rhizobacteria from field-grown Genetically Modified (GM) and non-GM maizes. Brazilian Archives of Biology and Technology, 57: 1-8.

Cappucino, J. C. and Sherman, N. (1992). Microbiolgy: A laboratory manual. Benjamin/Cummings Publishing Company, New York, pp 125-179.

Chaiharn, M. and Lumyong, S. (2009). Phosphate solubilization potential and stress tolerance of rhizobacteria from rice soil in Nothern Thailand. World Journal of Microbiology and Biotechnology, 25: 305-314.

Chamikara, H. J. M. P. (2020). Isolation, Identification and Characterization of Microorganisms from Different Cosmetic Samples. Post-Graduate Research Conference, Faculty of Graduate Studies, University of Kelaniya, Sri Lanka, pp. 60.

Dey, R., Pal, K. K., Bhatt, D. M. and Chauhan, S. M. (2004). Growth 
promotion and yield enhancement of peanut (Arachis hypogaea L.) by application of plant growth promoting rhizobacteria. Microbiological Research, 159: 371394.

Donate-Correa, J., Leon-Barrios M. and Perez-Galdona, R. (2005). Screening for plant growth-promoting rhizobacteria in Chamaecytisus proliferus (tagasaste), a forage treeshrub legume endemic to the Canary Islands. Plant Soil, 266: 261272.

Egamberdiyeva, D. (2005). Plant growth-promoting rhizobacteria isolated from a Calcisol in a semiarid region of Uzbekistan: biochemical characterization and effectiveness. Journal of Plant Nutrition and Soil Science, 168: 94-99. Elhaissoufi, W., Khourchi, S., Ibnyasser, A., Ghoulam, C., Rchiad, Z., Zeroual, Y., Lyamlouli, K. and Bargaz, A. (2020). Phosphate solubilizing rhizobacteria could have a stronger influence on wheat root traits and aboveground physiology than rhizosphere $\mathrm{P}$ solubilization. Froniers in Plant Science, 11: 979-985.

Fernández, V. P., Guzman, C. A., Peirce, T. M., McBeath, M., Khayet, L. and McLaughli, M. J. (2014). Effect of wheat phosphorous status on leaf surface properties and permeability to foliar-applied phosphorous. Plant and Soil, 384: 7-20.
Gracia de Salamone, I. E., Hynes, R. K. and Nelson, L. M. (2001). Cytokinin production by plant growthpromoting rhizobacteria and selected mutants. Canadian Journal of Microbiology, 47: 404-411.

Gulati, A., Sharma, N., Vyas, P., Sood, S., Rahi, P., Pathania, V. and Prasad, R. (2010). Organic acid production and plant growth promotion as a function of phosphate solubilization by Acinetobacter rhizosphaerae strain BIHB 723 isolated from the cold deserts of the trans-Himalayas. Archives of Microbiology, 192: 975983.

Gusain, Y. S., Kamal, R., Mehta, C. M., Singh, U. S. and Sharma, A. K. (2015). Phosphate solubilizing and indole-3-acetic acid producing bacteria from the soil of Garhwal Himalaya aimed to improve the growth of rice. Journal of Environmental Biology, 36: 301-307.

Gutierrez-Manero, F. J., B. RamosSolano, A. Probanza, J. Mehouachi, F. R. Tadeo and M. Talon (2001). The plantgrowth-promoting

rhizobacteria Bacillus pumilus and Bacillus licheniformis produce high amounts of physiologically active gibberellins. Physiologia Plantarum, 111: 206-211.

Gutierrez, C. K., Matsui, G. Y., Lincoln, D. E. and Lovell, C. R. (2009). Production of the phytohormone indole-3-acetic acid by the estuarine species of the genus Vibrio. Applied 
and Environmental Microbiology, 75: 2253-2258.

Hall, T.A. (1999). BioEdit: a userfriendly biological sequence alignment editor and analysis program for Windows 95/98/NT. Nucleic Acids Symposium Series, 41: 95-98.

Hamdali, H., Hafidi, M., Virolle, M. J. and Ouhdouch, Y. (2008). Rock phosphate solubilizing Actinimycetes: Screening for plant growth-promoting activities. World Journal of Microbiology and Biotechnology, 24: 2565-2575.

Jamil, A., Riaz, S., Ashraf, M. and Foolad, M. R. (2011). Gene expression profiling of plants under salt stress. Critical Reviews in Plant Sciences, 30: 435-458.

Jeon, J. S., Lee, S. S., Kim, H. Y., Ahn, T. S. and Song H. G. (2003). Plant growth promotion in soil by some inoculated microorganisms. Journal of Microbiology, 41: 271-276.

Joe, M. M., Deivaraj, S., Benson, A., Henrya, A. J. and Narendrakumar, G. (2018). Soil extract calcium phosphate media for screening of phosphate-solubilizing bacteria. Agriculture and Natural Resources, 52: 305-308.

Kang, Y., Cheng, J., Mei, L. and Yin, S. (2010). Screening and identification of plant growth-promoting rhizobacteria. Acta Microbiologica Sinica, 50: 853-857.

Khan, M. S., Zaidi, A., Ahemad, M., Oves, M. and Wani, P. A. (2010).
Plant growth promotion by phosphate solubilizing fungicurrent perspective. Archives of Agronomy and Soil Science, 56: 73-98.

Kimura, M. (1980). A simple method for estimating evolutionary rates of base substitutions through comparative studies of nucleotide sequences. Journal of Molecular Evolution, 16: 111-120.

Kumar, A., Maurya, B.R. and Raghuwanshi, R. (2014). Isolation and Characterization of PGPR and their effect on growth, yield and Nutrient content in wheat (Triticum aestivum L.). Biocatalysis and Agricultural Biotechnology, 3: 121128.

Kumar, S., Tamura, K., Jakobsen, I. B. and Nei, M. (2001). MEGA2: molecular evolutionary genetics analysis software. Bioinformatics, 17: 1244-1245.

Lucy, M., Reed, E. and Glick, B. R. (2004). Application of free living plant growth promoting rhizobacteria. Antonie van leeuwenhoek, 86: 1-25.

Marques, A. P. G. C., Pires, C., Moreira, H., Rangel, A. O. S. S. and Castro, P. M. L. (2010). Assessment of the plant growth promotion abilities of six bacterial isolates using Zea mays as indicator plant. Soil Biology and Biochemistry, 42: 1229-1235.

Mundra, S., Arora, R. and Stobdan, T. (2011). Solubilization of insoluble inorganic phosphates by a novel temperature, $\mathrm{pH}$, and salt tolerant 
yeast, Rhodotorula sp. PS4, isolated from sea buckthorn rhizosphere, growing in cold desert of Ladakh, India. World Journal of Microbiology and Biotechnology, 27: 2387-2396.

Murphy, J. and Riley J. P. (1962). A modified single solution method for the determination of phosphate in natural waters. Analytica Chimica Acta, 27: 31-36.

Nacoon, S., Jogloy, S., Riddech, N., Mongkolthanaruk, W., Kuyper, W. T. and Boonlue, S. (2020). Interaction between phosphate solubilizing bacteria and arbuscular mycorrhizal fungi on growth promotion and tuber inulin content of Helianthus tuberosus L. Scientific Reports, 10: 4916-4926.

Nautiyal, C. S. (1999). An efficient microbiological growth medium for screening phosphate solubilizing microorganisms. FEMS Microbiology Letters, 170: 265-270.

NCBI (2019). BLAST: Basic Local Alignment Search Tool. National Center for Biotechnology Information (NCBI), Bethesda, Maryland, USA. Available at http://www.ncbi.nlm.nih.gov/

BLAST (accessed on 28 November 2019).

Nutaratat, P., Monprasit, A. and Srisuk, N. (2017). High-yield production of indole-3-acetic acid by Enterobacter sp. DMKU-RP206, a rice phyllosphere bacterium that possesses plant growth-promoting traits. Biotechnology, 7: 1-15.
Ozdal, M., Ozdal, O. G., Sezen, A. and Algur, O. F. (2016). Biosynthesis of indole-3-acetic acid by Bacillus cereus immobilized cells. Cumhuriyet Science Journal, 37: 212222.

Saitou, N. and Nei, M. (1987). The neighbor-joining method: a new method for reconstructing phylogenetic trees. Molecular Biology and Evolution, 4: 406-425.

SAS Institute (1999). SAS/STAT User's Guide Version 8. SAS, Cary, NC.

Satyaprakash, M., Nikitha, T., Reddi E. U. B., Sadhana, B. and Satya Vani, S. (2017). Phosphorous and phosphate solubilizing Bacteria and their role in plant nutrition. International Journal of Current Microbiology and Applied Sciences, 6: 2133-2144.

Schippers, B., Bakker, A. W., Bakker, R. and Van Peer, R. (1990). Beneficial and deleterious effects of $\mathrm{HCN}$ producing pseudomonads on rhizosphere interactions. Plant Soil, 129: 75-83.

Swain, M. R., Naskar, S. K. and Ray, R. C. (2007). Indole-3-acetic acid production and effect on sprouting of yam (Dioscorea rotundata L.) mini setts by Bacillus subtilis isolated from culturable cowdung microflora. Polish Journal of Microbiology, 56:103110.

Thakur, A. and Parikh, S. C. (2018). Screening of groundnut plant associated rhizobacteria for multiple plant beneficial plant growth promoting traits. Journal of 
Plant Pathology and Microbiology, 9: 17.

Thompson, J. D., Gibson, T. J., Plewniak, F., Jeanmougin, F. and Higgins, D. G. (1997). The Clustal X windows interface: flexible strategies for multiple sequence alignment aided by quality analysis tools. Nucleic Acids Research, 24: 4876-4882.

Varsha-Narsian, J., Thakkar, J. and Patel, H. H. (1994). Inorganic phosphate solubilization by some yeast. Indian Journal of Microbiology, 35: 113-118.

Vincent, J.M. (1970). A Manual for the practical study of root nodule bacteria. Burgess and Son Ltd. Great Britain.

Walpola, B.C. and Arunakumara, K.K.I.U. (2015). Assessment of phosphate solubilization and indole acetic acid production in plant growth promoting bacteria isolated from green house soils of Gonjugun, South Korea. Journal of Tropical Agricultural Research and Extension, 18: 31-39.

Wani, P. A., Khan, M. S. and Zaidi, A. (2007). Co-inoculation of nitrogen fixing and phosphate solubilizing bacteria to promote growth, yield and nutrient uptake in chickpea. Acta Agronomica Hungeria, 55: 315323.

Weisburg, W. G., Barns, S. M., Pelletier, D. A. and Lane, D. J. (1991). 16S ribosomal DNA amplification for phylogenetic study. Journal of Bacteriology, 173: 697-703.

Yadav, J., Verma, J. P. and Tiwari, K. N. (2010). Effect of plant growth promoting rhizobacteria on seed germination and plant growth chickpea (Cicer arietinum L.) under in vitro conditions. Biological Forum, 2: 15-18. 